\title{
Classificação dos domicílios "indígenas" no Censo Demográfico 2000: subsídios para a análise de condições de saúde*
}

\author{
Gerson Luiz Marinho** \\ Ricardo Ventura Santos ${ }^{\star \star *}$ \\ Nilza de Oliveira Martins Pereira***
}

\begin{abstract}
A caracterização dos domicílios nos levantamentos censitários, que inclui as condições de habitação, saneamento básico, entre outros aspectos, juntamente com o perfil socioeconômico dos moradores, é de grande importância em análises sobre condições de saúde. No Brasil, acumulam-se evidências de que os povos indígenas apresentam desigualdades importantes em relação a outros segmentos da sociedade, com taxas de morbimortalidade em geral mais pronunciadas. Com base nos microdados do Censo Demográfico 2000, este trabalho analisa as frequências de domicílios cujos responsáveis se autoclassificaram "indígenas" e que residiam em domicílio coletivo ou improvisado na área rural dos municípios brasileiros. Para essas duas possibilidades de classificação, não são investigadas as características dos domicílios. Na análise para os grupos de cor/raça, os "indígenas" foram os que tiveram as maiores proporções de domicilios coletivos, mais frequentes no Centro-Oeste, especificamente em Mato Grosso. As frequências de domicílios "improvisados indígenas" também foram superiores aos de não-indígenas, incluindo "brancos", "pretos" e "pardos". Ao contrário dos coletivos, domicílios improvisados "indígenas" ocorreram em diferentes regiões do Brasil, com destaque para municípios na macrorregião Sul e em Mato Grosso do Sul. Para os municípios localizados fora da Amazônia Legal, onde em geral as Terras Indígenas apresentam pequenas dimensões, houve 1,5 mais domicilios "indígenas" classificados como improvisados do que na Amazônia Legal. Argumenta-se que, em parte, as mais elevadas frequências de domicilios coletivos "indígenas" devam-se a problemas de classificação por parte do Censo, já que as sociedades indígenas apresentam morfologias sociais e familiares próprias. As análises indicam a necessidade de aprimorar a forma de captação dos dados sobre as características domiciliares dos "indígenas" no âmbito dos levantamentos conduzidos pelo IBGE. Somente com a geração de informações considerando a diversidade étnica existente no Brasil será possível diminuir a "invisibilidade demográfica e epidemiológica" dos povos indígenas e, consequentemente, enfrentar as desigualdades em saúde.
\end{abstract}

Palavras-chave: Demografia indígena. Censos Demográficos. Desigualdades em saúde.

\footnotetext{
* Esse trabalho é produto da dissertação de mestrado do primeiro autor, defendida no Programa de Pós-Graduação de Epidemiologia em Saúde Pública da Escola Nacional de Saúde Pública, Fundação Oswaldo Cruz. Os autores agradecem à Coordenação de Aperfeiçoamento de Pessoal de Nível Superior (Capes) pela concessão de bolsa de estudos.

** Enfermeiro-epidemiologista, professor assistente do Departamento de Enfermagem de Saúde Pública, Escola de Enfermagem Anna Nery, Universidade Federal do Rio de Janeiro (EEAN/UFRJ).

${ }_{* * \star}$ Antropólogo, pesquisador titular da Escola Nacional de Saúde Pública, Fundação Oswaldo Cruz (Fiocruz) e professor associado do Departamento de Antropologia, Museu Nacional, Universidade Federal do Rio de Janeiro (UFRJ).

${ }^{* * \star \star}$ Estatística, Diretoria de Pesquisas do Instituto Brasileiro de Geografia e Estatística (IBGE).
} 


\section{Introdução}

Há uma notável carência de informações sociodemográficas sobre os povos indígenas no Brasil (COIMBRA et al., 2003; PAGLIARO et al., 2005). O desconhecimento da dinâmica demográfica desses povos é preocupante, pois, além da vulnerabilidade que apresentam, configuram um conjunto bastante heterogêneo, com mais de 200 povos e aproximadamente 180 línguas. Embora tenha ocorrido uma ampliação dos estudos sobre a demografia de povos indígenas nas últimas décadas (IBGE, 2005; PAGLIARO et al., 2005), as informações são ainda bastante limitadas diante da sociodiversidade indígena presente no país.

Dados demográficos, especialmente os de origem censitária, são fundamentais no delineamento das condições de vida e dos perfis de saúde-doença das populações. Nos Censos Demográficos de 1991 e 2000, a categoria "indígena" foi incluída no quesito cor/raça do questionário da amostra. ${ }^{1}$ Há um crescente número de estudos sobre a demografia indígena no Brasil a partir de análises dos dados censitários (AZEVEDO, 2000; KENNEDY; STEPHEN, 2000; IBGE, 2005; PERZ et al., 2008; PEREIRA et al., 2005, 2009).

Informações censitárias sobre os domicílios são importantes na caracterização das condições de vida das populações. No âmbito dos censos demográficos, incluindo aquele realizado em 2000, os domicílios foram classificados pelo IBGE (2000) em três categorias: permanentes, improvisados e coletivos ${ }^{2}$. Segundo o IBGE (2000, p. 15):

É permanente se foi construído para servir exclusivamente à habitação e tinha finalidade de servir de moradia a uma ou mais pessoas; é improvisado se localizado em unidade nãoresidencial (loja, fábrica, etc.) que não tinha dependências destinadas exclusivamente à moradia, mas que estava ocupado por morador(es). São exemplos de domicílios improvisados prédios em construção, vagões de trem, carroças, tendas, barracas, trailers, grutas, aqueles situados sob pontes, viadutos e etc. Já o domicílio coletivo é registrado quando no estabelecimento ou instituição a relação entre as pessoas que nele habitavam era restrita a normas de subordinação administrativa. Exemplos incluem hotéis, pensões, presídios, cadeias, penitenciárias, quartéis, postos militares, asilos, orfanatos, conventos, hospitais e clínicas (com internação), alojamentos de trabalhadores, motéis e campings.

É importante indicar que o IBGE apenas coleta informações que caracterizam os domicílios, como as questões relacionadas ao status socioeconômico e saneamento básico, caso tenham sido classificados como permanentes.

Do ponto de vista do processo saúde/ doença dos povos indígenas, o perfil epidemiológico é marcado por elevadas taxas de morbimortalidade devido a doenças infecciosas e parasitárias (SANTOS; COIMBRA Jr., 2003). Dados do Censo 2000 indicaram que a taxa de mortalidade infantil (TMI) dos "indígenas" (51,4 por mil nascidos vivos) era mais elevada do que a da população brasileira em geral $(30,1$ por mil), sendo inclusive superior àquelas registradas para crianças "pretas" e "pardas" (34,9 e 33,0 por mil, respectivamente) (IBGE 2005, p. 85). Há uma volumosa literatura que aponta para uma estreita relação entre taxas elevadas de mortalidade infantil e inadequadas condições de saneamento (WALDMAN et al., 1995; SANTOS; COIMBRA Jr., 2003; LUDWIG et al., 2003; CHOR; LIMA, 2005; CARDOSO et al., 2005; OLIVEIRA, 2008).

A partir dos microdados do Censo Demográfico 2000, o objetivo deste trabalho é analisar o perfil de um conjunto selecionado de variáveis relacionadas à classificação dos domicílios cujos responsáveis se declararam "indígena" na área rural dos municípios do Brasil, em comparação com aquelas das demais categorias de cor/raça.

\footnotetext{
1 O Censo Demográfico realizado em 1960 incluiu a coleta de dados sobre "indígenas". No entanto, há importantes limitações, inclusive no que diz respeito à cobertura. Além disso, os dados não chegaram a ser sistematicamente analisados. 2 Adota-se neste trabalho a nomenclatura "espécie do domicílio", que é aquela atribuída à variável que classifica os domicílios no questionário básico do Censo Demográfico 2000. Disponível em: <http://www.ibge.gov.br/censo/quest_ basico.pdf>. Acesso em: 08 nov. 2011.
} 


\section{População e métodos}

Esse estudo foi realizado a partir dos microdados do Censo Demográfico 2000. Foram selecionados os domicílios localizados na área rural dos 5.507 municípios então existentes no país. Optou-se pela área rural porque é nela que estão majoritariamente localizadas as Terras Indígenas oficialmente reconhecidas pelo Estado brasileiro.

O banco analisado foi criado a partir de dados obtidos pela geração de tabelas por meio do comando "arealist" do software Redatam (versão 5). Além de variáveis de identificação dos municípios, foram elencadas aquelas relativas à cor/raça (frequências absolutas e proporções de domicílios classificados como coletivos e improvisados, cujos responsáveis se autodeclararam "brancos", "pretos", "pardos", "amarelos" ou "indígenas"). Para cada um dos municípios, calcularam-se as frequências de domicílios permanentes, improvisados e coletivos, segundo as categorias de cor/raça. ${ }^{3}$

As análises foram conduzidas segundo macrorregiões, unidades da federação, municípios com Terra Indígena e municípios localizados na Amazônia Legal e fora dela. Foram calculadas razões de prevalências (RP) com intervalos de confiança (IC) de $95 \%$ para duas situações distintas. $\mathrm{Na}$ primeira, a categoria de referência foi constituída pelos domicílios "indígenas" comparados àqueles cujos responsáveis eram das demais categorias de cor/raça; na segunda, utilizaram-se como referência domicílios indígenas em municípios da Amazônia Legal.

Para a análise referente à Amazônia Legal, foi considerado o conjunto de 756 municípios a ela pertencente em 2000. A malha territorial e a listagem dos municípios foram extraídas do site do IBGE. ${ }^{4} \mathrm{~A}$ Amazônia Legal compreende uma extensão de aproximadamente $5.109 .812 \mathrm{~km}^{2}$, majoritariamente na macrorregião Norte, e corresponde a $61 \%$ do território nacional, concentrando a maioria das Terras Indígenas (aproximadamente 99\% da extensão das Terras Indígenas do Brasil).

Para fins desse trabalho, foi empregado o conceito de "rural específico", termo utilizado pelo IBGE (2005) para denominar a área rural dos municípios com Terras Indígenas. Das 734.127 pessoas que se autodeclararam "indígenas" em 2000, 350 mil viviam em situação de domicílio rural, das quais $86,7 \%$ estavam em municípios com Terras Indígenas (304 mil).

A análise estatística foi feita utilizando-se os softwares SPSS ${ }^{\circledR} 17.0$ e R (versão 2.10.1). Foi também empregado o programa TerraView ${ }^{\circledR}$ 3.2.0 para a geração de mapas.

\section{Resultados}

\section{Municípios com domicílios "indígenas"}

Do total de 5.507 municípios existentes no país em 2000, em 1.445 (26,2\%) havia pelo menos um domicílio cujo responsável se autodeclarou "indígena" na área rural. As porcentagens segundo macrorregiões foram: $53,2 \%$ no Norte; $24,8 \%$ no Nordeste; $18,3 \%$ no Sudeste; $25,2 \%$ no Sul e $36,3 \%$ no Centro-Oeste.

As maiores frequências de municípios nos quais havia domicílios "indígenas" ocorreram nas macrorregiões Norte e Centro-Oeste (Tabela 1). Em 1.403 municípios $(25,4 \%)$ foi registrado pelo menos um domicílio permanente "indígena". Verificou-se ainda que, em todo o país, em $134(2,4 \%)$ municípios havia domicílio improvisado "indígena" e, em 67 (1,2\%), domicílio coletivo "indígena". Dos 449 municípios da macrorregião Norte, aproximadamente 9\% apresentaram pelo menos um domicílio improvisado "indígena"; em 5\% deles havia pelo menos um domicílio coletivo "indígena". No Centro-Oeste, as frequências foram

\footnotetext{
${ }^{3}$ A partir deste ponto será adotada nomenclatura específica para fazer referência aos domicílios, de acordo com a cor/ raça declarada pelo responsável e também a espécie. Assim, por exemplo, chamou-se domicílio "indígena" coletivo aquele cujo responsável se declarou "indígena" e, concomitantemente, foi classificado como coletivo. O mesmo se aplica para os domicílios classificados como improvisados.

4 Disponível em: <http://www.ibge.gov.br/home/geociencias/geografia/mapas_doc5.shtm>. Acesso em 09 nov. 2009.
} 
semelhantes para coletivos e improvisados. No Sul, houve oito vezes mais municípios com a presença de pelo menos um domicílio improvisado "indígena" em relação aos coletivos "indígenas" (Tabela 1).

A Tabela 2 mostra a distribuição dos domicílios de acordo com cor/raça do responsável na área rural de cada uma das macrorregiões. Considerando toda a área rural do país, havia 72.457 domicílios cujos responsáveis se declararam "indígena", dos quais $2.537(3,5 \%)$ foram classificados como improvisados e $3.188(4,4 \%)$ como coletivos. Houve uma frequência inferior a 5.000 para domicílios cujo responsável se declarou "amarelo" na maioria das macrorregiões, com exceção do Sudeste. As frequências para "indígenas" são também relativamente baixas, variando de 5.477 a 30.702 no Sudeste e Norte, respectivamente. Para todas as categorias de cor/ raça, com exceção dos "indígenas" no Centro-Oeste, as proporções de domicílios permanentes ultrapassaram os $90 \%$. Para os improvisados, a ampla maioria dos valores foi menor ou igual a $4 \%$, havendo cinco situações de valores mais elevados, das quais três referem-se a domicílios "indígenas" localizados no Sudeste $(4,4 \%)$, Sul $(6,6 \%)$ e Centro-Oeste $(4,1 \%)$. No caso dos domicílios coletivos, verificou-se que, considerando as categorias de cor/ raça segundo macrorregião, a maioria dos valores foi menor ou igual a $3 \%$. As proporções acima de $3 \%$ correspondem a cinco situações, entre as quais duas foram para domicílios "indígenas" no Norte (3,3\%) e no Centro-Oeste (13,6\%) (Tabela 2).

No caso dos domicílios "indígenas", foram registradas proporções de improvisados que variaram de $1,9 \%$ no Nordeste a $6,6 \%$ no Sul. Para os coletivos, os valores variaram de $0,6 \%$ no Sul a $13,6 \%$ no Centro-Oeste (Tabela 2). As frequências de domicílios não-permanentes (ou seja, improvisados ou coletivos) variaram de $3,1 \%$ no Nordeste a $17,7 \%$ no Centro-Oeste, totalizando $7,9 \%$ no país. Nota-se que aproximadamente um domicílio "indígena" em cada cinco da macrorregião Centro-Oeste não teve informações sobre as características domiciliares coletadas, por ter sido considerado improvisado ou coletivo.

As razões de prevalência indicam que os domicílios indígenas improvisados, quando comparados àqueles com responsáveis "brancos", foram mais frequentes em todas as macrorregiões, sendo que no Sul e Sudeste as prevalências chegaram a ser seis vezes mais elevadas (Tabela 3 ). No total da área rural do Brasil, os domicílios improvisados "indígenas" foram duas vezes mais frequentes do que os improvisados "brancos". Domicílios coletivos "indígenas" foram mais frequentes não somente quando comparados aos coletivos "brancos", mas também aos pretos" e "pardos" nas macrorregiões Norte, Nordeste e Centro-Oeste. Em todo o país, os domicílios coletivos "indígenas" foram duas, três e quatro vezes mais frequentes do que "pretos", "brancos" e "pardos", respectivamente (Tabela 3).

TABELA 1

Número de municípios com domicílios cujo responsável se autodeclarou "indígena", por espécie do domicílio, segundo as macrorregióes

Brasil rural - 2000

\begin{tabular}{|c|c|c|c|c|c|c|c|}
\hline \multirow{3}{*}{ Macrorregiões } & \multirow{3}{*}{ Total } & \multicolumn{6}{|c|}{ Municípios com domicílio "indígena”, por espécie } \\
\hline & & \multicolumn{2}{|c|}{ Permanente } & \multicolumn{2}{|c|}{ Improvisado } & \multicolumn{2}{|c|}{ Coletivo } \\
\hline & & N. abs. & $\%$ & N. abs. & $\%$ & N. abs. & $\%$ \\
\hline Norte & 449 & 235 & 52,3 & 40 & 8,9 & 21 & 4,7 \\
\hline Nordeste & 1.787 & 438 & 24,5 & 25 & 1,4 & 6 & 0,3 \\
\hline Sudeste & 1.667 & 297 & 17,8 & 8 & 0,5 & 8 & 0,5 \\
\hline Sul & 1.158 & 280 & 24,2 & 37 & 3,2 & 4 & 0,3 \\
\hline Centro-Oeste & 446 & 153 & 34,3 & 24 & 5,4 & 28 & 6,3 \\
\hline Brasil & 5.507 & 1.403 & 25,5 & 134 & 2,4 & 67 & 1,2 \\
\hline
\end{tabular}

Fonte: IBGE. Microdados do Censo Demográfico 2000. 
TABELA 2

Domicílios, por macrorregião, segundo a cor ou raça do responsável e a espécie do domicílio Brasil rural $-\mathbf{2 0 0 0}$

\begin{tabular}{|c|c|c|c|c|c|c|c|c|c|c|}
\hline \multirow{2}{*}{$\begin{array}{l}\text { Cor ou raça do } \\
\text { responsável } \\
\text { e espécie do } \\
\text { domicílio }\end{array}$} & \multicolumn{2}{|c|}{ Norte } & \multicolumn{2}{|c|}{ Sudeste } & \multicolumn{2}{|c|}{ Sul } & \multicolumn{2}{|c|}{ Centro Oeste } & \multicolumn{2}{|c|}{ Brasil } \\
\hline & N. abs. & $\%$ & N. abs, & $\%$ & N. abs. & $\%$ & N. abs. & $\%$ & N. abs. & $\%$ \\
\hline Branca & 185.364 & 100,00 & 1.017 .487 & 100,00 & 1.087 .661 & 100,00 & 194.110 & 100,00 & 3.417 .088 & 100,00 \\
\hline Permanentes & 179.935 & 97,07 & 988.020 & 97,10 & 1.068 .147 & 98,21 & 184.963 & 95,29 & 3.345 .278 & 97,9 \\
\hline Improvisados & 4.159 & 2,24 & 6.741 & 0,66 & 11.134 & 1,02 & 6.320 & 3,26 & 34.542 & 1,01 \\
\hline Coletivos & 1.270 & 0,68 & 22.726 & 2,23 & 8.380 & 0,77 & 2.827 & 1,46 & 37.268 & 1,09 \\
\hline Preta & 70.499 & 100,00 & 146.819 & 100,00 & 45.940 & 100,00 & 28.661 & 100,00 & 632.709 & 100,00 \\
\hline Permanentes & 67.116 & 95,20 & 139.779 & 95,20 & 43.921 & 95,61 & 25.810 & 90,05 & 612.467 & 96,8 \\
\hline Improvisados & 2.673 & 3,79 & 2.004 & 1,36 & 1.300 & 2,83 & 1.988 & 6,94 & 12.168 & 1,92 \\
\hline Coletivos & 710 & 1,01 & 5.036 & 3,43 & 719 & 1,57 & 863 & 3,01 & 8.074 & 1,28 \\
\hline Parda & 497.326 & 100,00 & 595.934 & 100,00 & 152.488 & 100,00 & 191.672 & 100,00 & 3.396 .264 & 100,00 \\
\hline Permanentes & 480.952 & 96,71 & 575.718 & 96,6 & 146.723 & 96,22 & 178.296 & 93,02 & 3.316 .577 & 97,65 \\
\hline Improvisados & 12.169 & 2,45 & 6.996 & 1,17 & 4.257 & 2,79 & 8.789 & 4,59 & 51.000 & 1,50 \\
\hline Coletivos & 4.205 & 0,85 & 13.220 & 2,22 & 1.508 & 0,99 & 4.587 & 2,39 & 28.687 & 0,84 \\
\hline Amarela & 1.985 & 100,00 & 8.526 & 100,00 & 3.551 & 100,00 & 1.513 & 100,00 & 20.002 & 100,00 \\
\hline Permanentes & 1.897 & 95,57 & 8.023 & 94,10 & 3.525 & 99,27 & 1.480 & 97,82 & 19.274 & 96,36 \\
\hline Improvisados & 57 & 2,87 & 21 & 0,25 & 15 & 0,42 & 20 & 1,32 & 176 & 0,88 \\
\hline Coletivos & 31 & 1,56 & 482 & 5,65 & 11 & 0,31 & 13 & 0,86 & 552 & 2,76 \\
\hline Indígena & 30.702 & 100,00 & 5.477 & 100,00 & 7.854 & 100,00 & 13.581 & 100,00 & 72.457 & 100,00 \\
\hline Permanentes & 28.733 & 93,59 & 5.152 & 94,10 & 7.285 & 92,76 & 11.184 & 82,35 & 66.732 & 92,10 \\
\hline Improvisados & 947 & 3,08 & 239 & 4,36 & 520 & 6,62 & 553 & 4,07 & 2.537 & 3,50 \\
\hline Coletivos & 1.022 & 3,33 & 86 & 1,57 & 49 & 0,62 & 1.844 & 13,58 & 3.188 & 4,40 \\
\hline Total & 785.876 & 100,00 & 1.774 .243 & 100,00 & 1.297 .494 & 100,00 & 429.537 & 100,00 & 7.538 .520 & 100,00 \\
\hline Permanentes & 758.633 & 96,53 & 1.716 .692 & 96,80 & 1.269 .601 & 97,85 & 401.733 & 93,53 & 7.360 .328 & 97,64 \\
\hline Improvisados & 20.005 & 2,55 & 16.001 & 0,90 & 17.226 & 1,33 & 17.670 & 4,11 & 100.423 & 1,33 \\
\hline Coletivos & 7.238 & 0,92 & 41.550 & 2,34 & 10.667 & 0,82 & 10.134 & 2,36 & 77.769 & 1,03 \\
\hline
\end{tabular}

Fonte: IBGE. Microdados do Censo Demográfico 2000.

Domicilios improvisados e coletivos "indígenas" por unidades da Federação

Registrou-se pelo menos um domicílio improvisado "indígena" em 20 Estados brasileiros, englobando todos das macrorregiões Norte, Centro-Oeste e Sul. Quanto ao número de municípios por Estado com domicílios improvisados "indígenas", as mais elevadas frequências foram observadas no Paraná e no Rio Grande do Sul (16 municípios para cada um), seguidos por Amazonas (14 municípios) e Pará (11 municípios). Assim, a maior quantidade em termos de número de municípios ocorreu na macrorregião Sul do país (resultados não apresentados). A distribuição percentual dos domicílios improvisados "indígenas" para os Estados sugere que, em relação aos coletivos, aqueles apresentam uma distribuição mais homogênea pelo território brasileiro: $17,9 \%$ no Mato Grosso do Sul; $16,7 \%$ no Pará; $14,2 \%$ no Amazonas; e $11,6 \%$ no Rio Grande do Sul. Essa aparente homogeneidade relaciona-se ao fato de que $82,9 \%$ dos municípios $(111 / 134)$ apresentaram proporções inferiores a $1 \%$ para o total de domicílios improvisados "indígenas", o que representa $41,1 \%$ (1.042/2.537) desses domicílios no Brasil, em 2000.

Os municípios com as maiores proporções de domicílios improvisados "indígenas" 


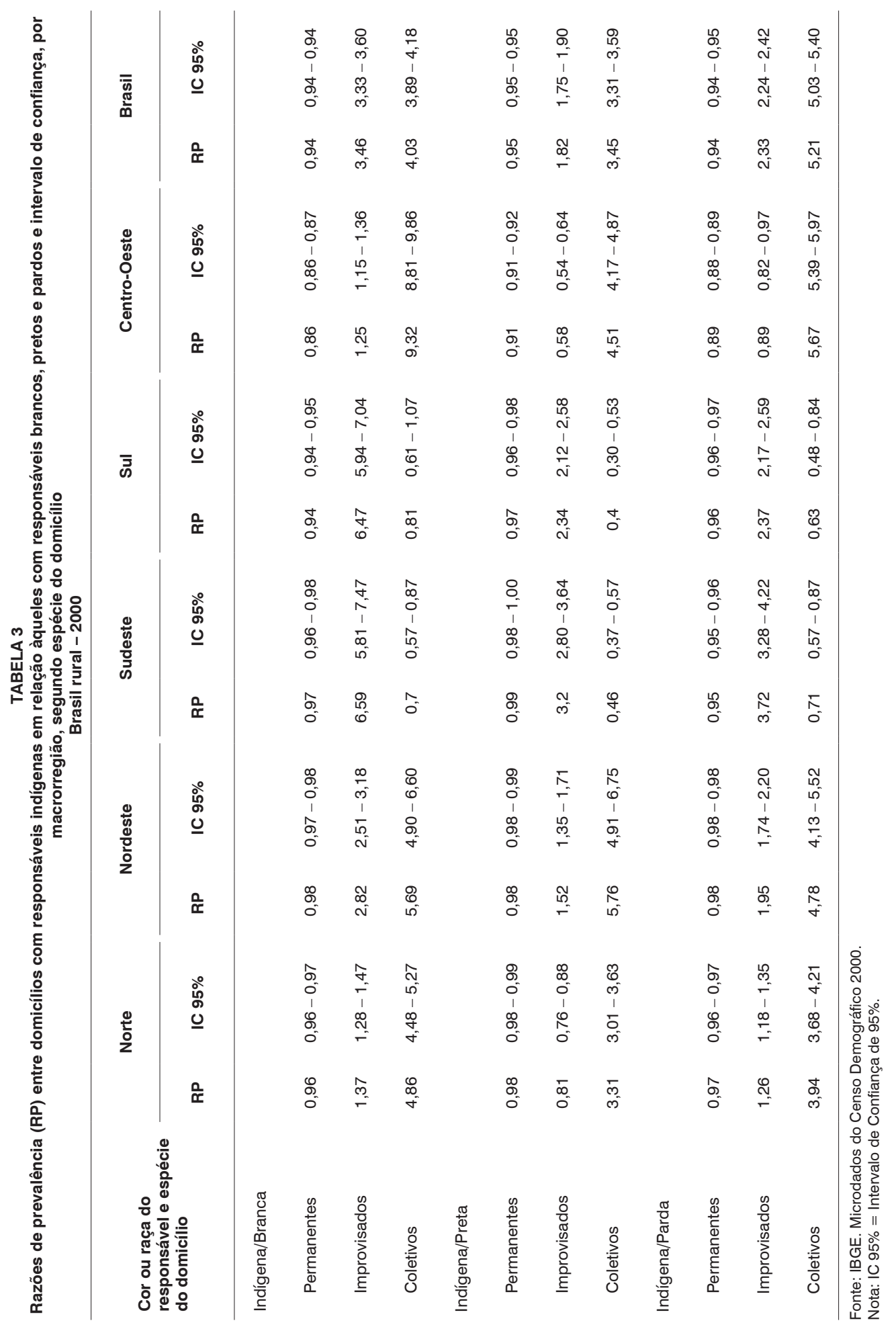


$(n=34)$ estavam nas macrorregiões Norte, Centro-Oeste e Sul. Nota-se ainda que a maioria dos municípios com pelo menos um domicílio improvisado "indígena" estava no Norte do país (Mapa 1 ). Um pequeno conjunto de sete municípios apresentou $34,4 \%$ do total de domicílios improvisados "indígenas" existentes no país. Desses, um está localizado no Amazonas (São Gabriel da Cachoeira - 4,7\%), um no Pará (Itupiranga $-9,0 \%$ ), dois em Minas Gerais (Bertópolis $-3,8 \%$ e Santa Helena de Minas - 3,2\%), um no Rio Grande do Sul (Salto do Jacuí - 5,2\%) e dois no Mato Grosso do Sul (Dourados $5,1 \%$ e Miranda $-3,4 \%$ ). Três municípios do Mato Grosso do Sul (Dourados, Miranda e Paranhos) concentraram aproximadamente 9,0\% dos domicílios improvisados "indígenas" do país.

Em 17 Estados foi registrado ao menos um domicílio coletivo "indígena", com destaque para Mato Grosso (56,6\% do total de domicílios coletivos "indígenas" do país), seguido por Roraima (16,0\%) e Amazonas

MAPA 1

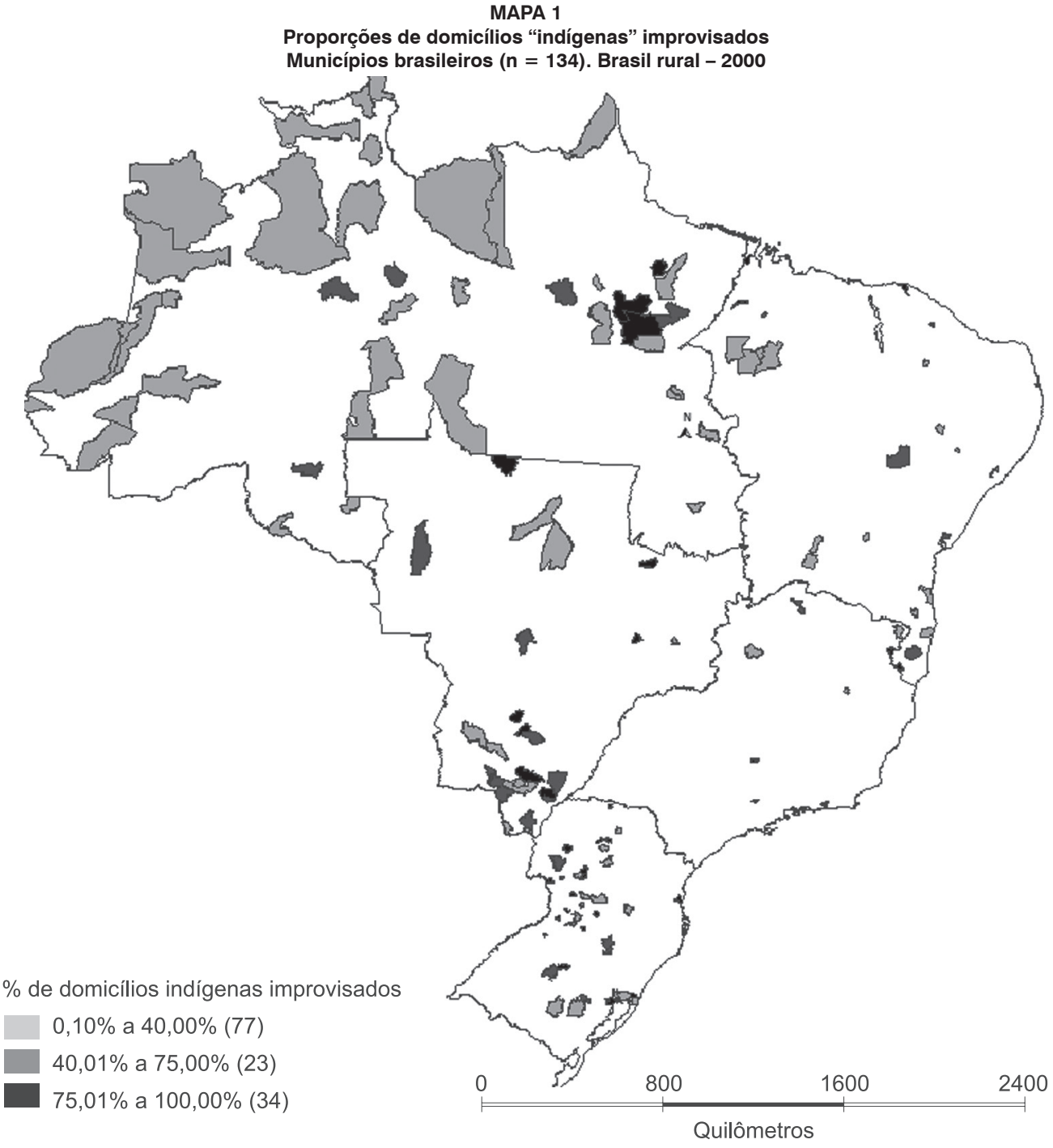

Fonte: IBGE. Microdados do Censo Demográfico 2000. 
$(8,7 \%)$. No Norte, onde está a maior proporção de pessoas autodeclaradas "indígenas", todos os Estados, com exceção de Rondônia, apresentaram domicílios coletivos "indígenas". No Nordeste, quatro Estados registraram domicílios coletivos "indígenas", ainda que em proporções baixas, que variaram de $0,2 \%$ no Ceará a 3,2\% no Maranhão (percentuais relativos ao total do país), distribuídos em apenas seis municípios. Para a macrorregião Sudeste, a maior proporção foi observada em São Paulo (2,0\%), onde um conjunto de seis municípios (Agudos, Jaboticabal, Salto de Pirapora, Santa Isabel, Tremembé e Vera Cruz) apresentou 65 domicílios coletivos "indígenas". Para a área rural desses municípios, todos os domicílios "indígenas" foram classificados como coletivos, variando de 3 a 22 domicílios.
Assim, para tais municípios, os domicílios "indígenas" foram $100 \%$ classificados como coletivos. Em oito Estados, as proporções foram inferiores a $1 \%$ da totalidade dos domicílios coletivos "indígenas" e em outros cinco as proporções variaram entre 1,2\% e $3,2 \%$, o que representa valores muito baixos se comparados àqueles encontrados em Mato Grosso.

Como já apontado, a maioria de domicílios coletivos "indígenas" registrados no Censo 2000 foi observada em Mato Grosso. Do total de 3.188 domicílios coletivos "indígenas" em todo o Brasil, mais de $40 \%$ localizavam-se em apenas cinco municípios de Mato Grosso: Campinápolis (11,9\% do total do país); Barra do Garças (11,5\%); Gaúcha do Norte $(7,8 \%)$, Canarana $(6,2 \%)$ e Água Boa (4,5\%) (Mapa 2).

MAPA 2

Municípios com as maiores proporções de domicílios coletivos com responsáveis "indígenas" em relação ao total no Brasil rural Estado do Mato Grosso - 2000

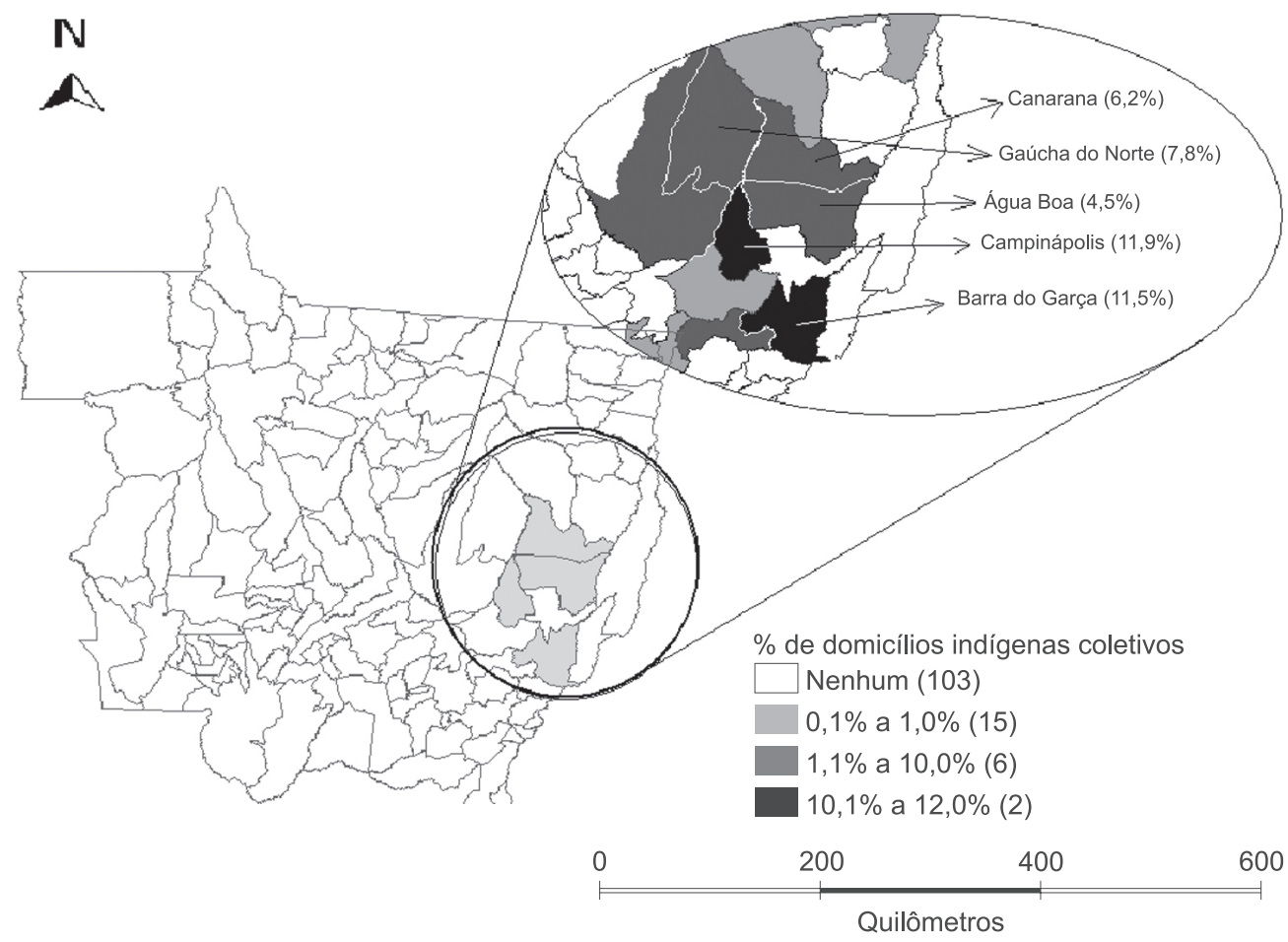

Fonte: IBGE. Microdados do Censo Demográfico 2000. 
Domicílios improvisados e coletivos "indígenas" nos municípios da Amazônia Legal

No conjunto dos dez municípios com as maiores proporções de domicílios improvisados "indígenas", seis situam-se fora da Amazônia Legal, sendo três deles no Mato Grosso do Sul. Para os domicílios coletivos "indígenas", a totalidade estava localizada na Amazônia Legal, sendo seis deles em Mato Grosso. A partir dessa análise, conclui-se que os domicílios improvisados "indígenas" estavam mais dispersos geograficamente, mas com tendência de concentração fora da Amazônia Legal.

Dos municípios brasileiros existentes em 2000, 756 localizavam-se dentro da Amazônia Legal e 4.751 fora dessa área. Os Gráficos 1 e 2 mostram o padrão contrastante da distribuição dos domicílios improvisados e coletivos, respectivamente, comparando os municípios dentro e fora da Amazônia Legal, segundo as categorias de cor/raça. ${ }^{5}$ Do total de domicílios cujo responsável se autodeclarou "indígena", no Brasil, conforme já sinalizado, 7,1\% foram classificados como "improvisados", dos quais 2,9\% estavam na Amazônia Legal e 4,2\% fora dela. Não obstante, do total de $8,3 \%$ que foram classificados como "coletivos indígenas" no país, 7,5\% estavam na Amazônia Legal e somente $0,8 \%$ fora. Para todas as categorias de cor/raça, com exceção dos "indígenas", as proporções de "improvisados" foram consistentemente superiores na Amazônia Legal (variando de 2,3\% para "pardos" a $3,2 \%$ para "pretos"). Quanto aos "coletivos", segundo as categorias de cor/raça, houve poucas diferenças entre as localizações dentro e fora da Amazônia, com exceção dos "indígenas", para os quais as diferenças foram da ordem de 10 vezes $(7,5 \%$ e $0,8 \%$, respectivamente).

Observam-se, portanto, padrões divergentes dos domicílios "indígenas" em relação às demais categorias de cor/raça. Para os improvisados, a proporção no caso dos domicílios "indígenas" foi maior naqueles municípios fora da Amazônia Legal (quase três vezes maior em relação a domicílios "pretos" e "pardos"; e quatro vezes maior que "brancos"). Para a categoria coletivo, a porcentagem é mais elevada para os "indígenas" na Amazônia Legal (ainda que concentrados em alguns municípios do Mato Grosso) (Gráficos 1 e 2).

As razões de prevalência para os domicílios de acordo com as categorias de cor/ raça mostraram que, na Amazônia Legal, houve maior prevalência de domicílios improvisados para as categorias "branco", "preto" e "pardo". Entretanto, para os "indígenas", houve uma prevalência maior para os domicílios fora da Amazônia Legal (Tabela 4).

TABELA 4

Razões de prevalência (RP) entre domicílios nos municípios dentro e fora da Amazônia Legal (AL) e intervalo de confiança, por cor ou raça dos responsáveis, segundo espécie do domicílio Brasil rural $\mathbf{- 2 0 0 0}$

\begin{tabular}{|c|c|c|c|c|c|c|c|c|}
\hline \multirow{2}{*}{$\begin{array}{l}\text { Espécie do } \\
\text { domicílio }\end{array}$} & \multicolumn{2}{|c|}{ Branco } & \multicolumn{2}{|c|}{ Preto } & \multicolumn{2}{|c|}{ Pardo } & \multicolumn{2}{|c|}{ Indígena } \\
\hline & RP & IC 95\% & $\mathbf{R P}$ & IC 95\% & RP & IC $95 \%$ & $\mathbf{R P}$ & IC 95\% \\
\hline \multicolumn{9}{|c|}{$A L /$ Fora da $A L$} \\
\hline Permanentes & 0,99 & $0,99-0,99$ & 0,99 & $0,99-0,99$ & 0,99 & $0,99-0,99$ & 0,94 & $0,94-0,95$ \\
\hline Improvisados & 2,68 & $2,61-2,74$ & 2,00 & $1,93-2,08$ & 1,82 & $1,79-1,85$ & 0,68 & $0,63-0,74$ \\
\hline Coletivos & 0,75 & $0,73-0,78$ & 0,71 & $0,67-0,75$ & 1,01 & $0,98-1,04$ & 9,68 & $8,53-10,99$ \\
\hline
\end{tabular}

Fonte: Microdados do Censo Demográfico 2000.

Nota: IC 95\% = Intervalo de Confiança de 95\%.

Para esta análise são considerados todos os domicílios em área rural, inclusive municípios que apresentaram menos que dez domicílios.

\footnotetext{
${ }^{5}$ Foram excluídos dessa análise os responsáveis de domicílios que se autodeclararam "amarelos" devido à baixa frequência. $\mathrm{Na}$ área rural dos municípios, considerando todo o país, havia 552 domicílios "amarelos" coletivos (38 na Amazônia Legal e 514 fora) e 176 domicílios "amarelos" improvisados (67 na Amazônia Legal e 109 fora).
} 


\section{GRÁFICO 1}

Distribuição dos domicílios improvisados situados em municípios dentro e fora da Amazônia Legal, por cor ou raça do responsável

Brasil rural $\mathbf{- 2 0 0 0}$

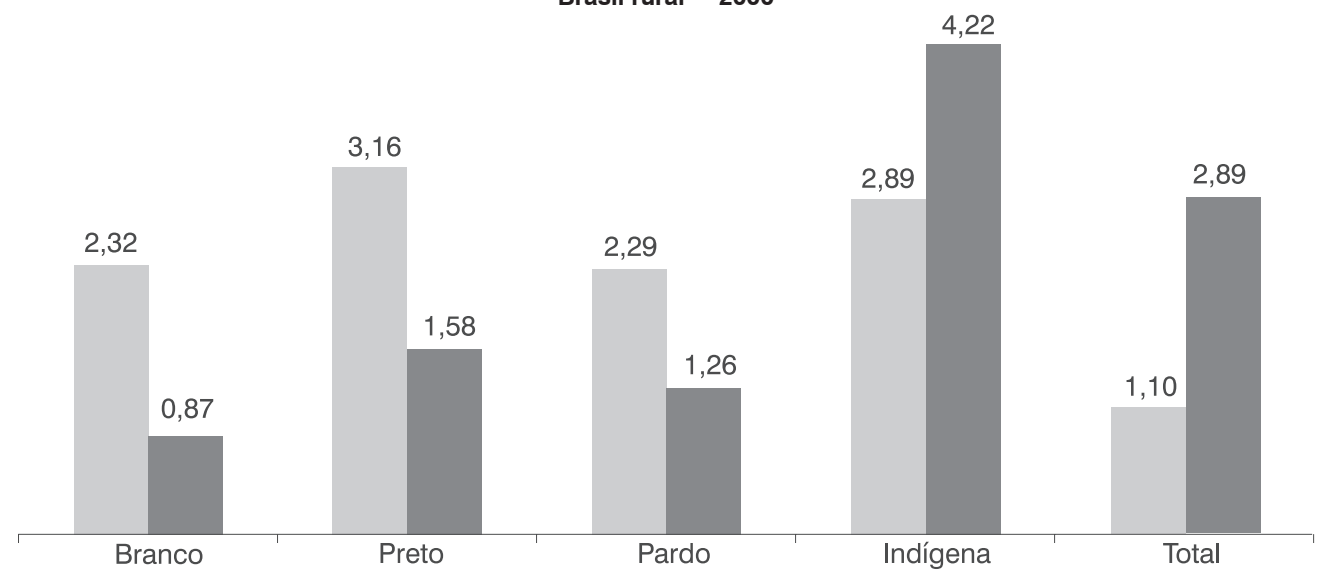

Amazônia Legal (\%) —Fora Amaz. Legal (\%)

Fonte: IBGE. Microdados do Censo Demográfico 2000.

GRÁFICO 2

Distribuição dos domicílios coletivos situados em municípios dentro e fora da Amazônia Legal, por cor ou raça do responsável

Brasil rural -2000

\subsection{9}

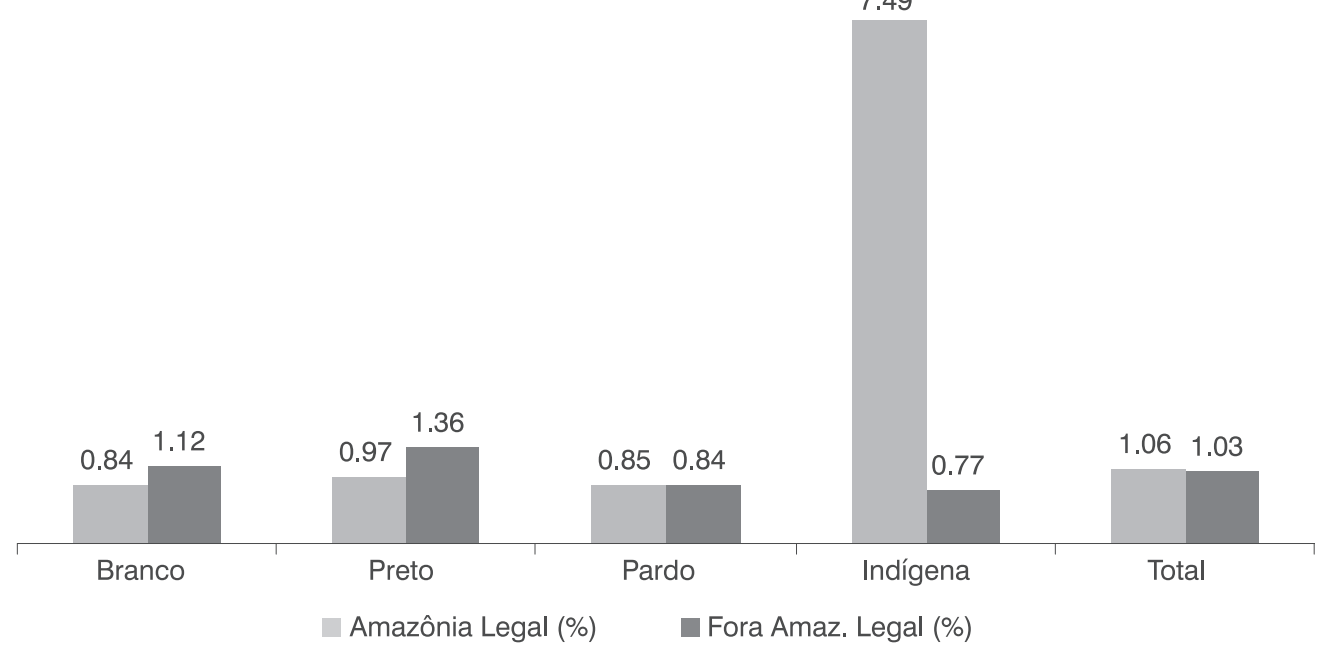

Fonte: IBGE. Microdados do Censo Demográfico 2000. 
Para esta análise são considerados todos os domicílios em área rural, inclusive municípios que apresentaram menos que dez domicílios.

\section{Domicílios "indígenas" nos municípios com Terras Indígenas}

Em 2000, 437 (7,9\%) municípios brasileiros apresentavam Terras Indígenas - TI dentro de seus limites territoriais (IBGE, 2005), com concentração na macrorregião Norte $(38 \%)$ e a menor proporção no Sudeste, onde apenas 5,9\% dos municípios possuíam TI.

No conjunto dos 437 municípios com TI, foram registrados 58.196 domicílios cujos responsáveis se declararam "indígena" (Tabela 5). Do total de 2.537 domicílios improvisados "indígenas", 81,1\% estavam localizados nos municípios com TI (aproximadamente um em cada cinco domicílios improvisados "indígenas" estava em municípios sem TI). Quanto aos coletivos, do total de 3.188 domicílios no país, 2.954 (92,7\%) situavam-se em municípios com TI. Nota-se, ainda, que os domicílios improvisados "indígenas" estavam presentes em municípios que têm $\mathrm{Tl}$ em todas as macrorregiões do país (Tabela 5). Para a categoria coletivo, os maiores registros ocorreram em municípios do Centro-Oeste e Norte, em consonância com os achados apresentados anteriormente.

\section{Discussão}

Os censos demográficos no Brasil ocorrem, em geral, a cada dez anos e coletam grande quantidade de dados sobre os domicílios. As informações geradas nos censos são fundamentais para formulação e implementação de políticas públicas, incluindo a alocação dos investimentos governamentais (IBGE, 2000).

Para os indígenas vem ocorrendo, há algum tempo, um esforço para reduzir a "invisibilidade demográfica e epidemiológica" à qual estão submetidos (COIMBRA Jr.; SANTOS, 2000). Um importante marco nesse sentido foi a inclusão da temática indígena na Constituição Federal de 1988, que garante o respeito e o reconhecimento à sociodiversidade indígena (GARNELO et al., 2003; SANTOS et al., 2008; PEREIRA, 2009). Em 1991 ocorreu a inclusão da categoria "indígena" no Censo Demográfico e, nos anos seguintes, eventos ligados às Conferências de Saúde culminaram, em 1999, com a criação do Subsistema de Atenção à Saúde dos Povos Indígenas e dos Distritos Sanitários Especiais Indígenas (DSEI). Nas investigações censitárias de 1991 e 2000, mesmo se tratando de uma categoria genérica, ${ }^{6}$ pois não compreende a coleta de dados sobre filiação étnica específica, a alternativa "indígena" como possibilidade de resposta da variável cor/raça foi reconhecida como

TABELA 5

Domicílios com responsáveis "indígenas” nos municípios com Terras Indígenas (n. = 437), por espécie do domicílio, segundo macrorregiões Brasil rural - $\mathbf{2 0 0 0}$

\begin{tabular}{|c|c|c|c|c|c|c|}
\hline \multirow{2}{*}{ Macrorregiões } & \multicolumn{2}{|c|}{ Permanentes } & \multicolumn{2}{|c|}{ Improvisados } & \multicolumn{2}{|c|}{ Coletivos } \\
\hline & N. abs. & $\%$ & N. abs. & $\%$ & N. abs. & $\%$ \\
\hline Norte & 27.479 & 51,6 & 847 & 41,2 & 983 & 33,3 \\
\hline Nordeste & 8.378 & 15,7 & 215 & 10,4 & 144 & 4,8 \\
\hline Sudeste & 1.968 & 3,7 & 192 & 9,3 & 0 & 0 \\
\hline Sul & 5.084 & 9,6 & 361 & 17,5 & 0 & 0 \\
\hline Centro-Oeste & 10.275 & 19,3 & 443 & 21,5 & 1.827 & 61,8 \\
\hline Brasil & 53.184 & 100,0 & 2.058 & 100,0 & 2.954 & 100,0 \\
\hline
\end{tabular}

Fonte: IBGE. Microdados do Censo Demográfico 2000.

\footnotetext{
${ }^{6}$ Em vários países, inclusive no Brasil, a maneira como os dados sobre a categoria "indígena" são captados pelos censos pode gerar o que alguns antropólogos e demógrafos denominam de uma "identidade indígena genérica". Conforme já referido, há no Brasil uma enorme sociodiversidade indígena, com mais de 200 diferentes etnias. Para maiores informações, vide Azevedo (2006).
} 
um avanço no sentido de melhor conhecer a demografia dos povos indígenas do Brasil, com importantes implicações no plano da saúde (PAGLIARO et al., 2005; SANTOS et al., 2008; PEREIRA, 2009). Nesse sentido, aconteceram importantes avanços no recém-concluído Censo Demográfico de 2010 no que diz respeito aos indígenas, uma vez que foram acrescentadas perguntas sobre filiação étnica específica e língua falada, entre outras. ${ }^{7}$

Diversos estudos sinalizam que, para a população indígena no Brasil, questões relativas à morbimortalidade estão estreitamente relacionadas às condições de marginalidade socioeconômica, o que se exemplifica pelas precárias condições de saneamento das aldeias e inadequados serviços de saúde (SANTOS; COIMBRA Jr., 2003; ESCOBAR et al., 2003; CARDOSO et al., 2005; ABRASCO, 2009). Comumente observa-se que nas aldeias há ausência de infraestrutura destinada à coleta dos dejetos e inexistência de água potável, propiciando, assim, amplas condições para disseminação de agentes infecciosos e parasitários, com consequências no quadro de saúde, destacando-se as doenças diarréicas.

Conforme já referido, no âmbito dos censos, as características domiciliares são coletadas somente para os domicílios classificados como permanentes. Como demonstrado neste trabalho, os "indígenas" no Censo 2000 mostraram-se como a categoria com o maior percentual de ausência de informações para os domicílios, já que houve proporcionalmente uma maior frequência de domicílios classificados como coletivos e improvisados.

O conhecimento sobre a situação dos domicílios permite analisar questões que caracterizam o modo como a população investigada dispõe de serviços básicos. Dessa forma, Alves e Cavenaghi (2006) mencionam que, de maneira ideal, para serem considerados habitáveis, os domicílios devem apresentar requisitos mínimos de construção e conservação, com condições adequadas de oferta de luz, água, esgotamento sanitário e coleta de lixo. Os autores indicam ainda que, de forma geral, as condições de moradia da população latino-americana são marcadas por altos graus de desigualdade. De acordo com o IBGE, o número de domicílios no Brasil tem aumentado acima do ritmo de crescimento da população e apenas uma reduzida parcela da população possui domicílio com pequena densidade de moradores, enquanto outra parcela considerável reside em domicílios pequenos e deficientes, com alta densidade de moradores. Os censos demográficos vêm aperfeiçoando a forma de investigação sobre as características dos domicílios, apesar de ainda existirem muitas lacunas. Tais melhorias na coleta de informações são importantes para identificar a oferta e a demanda de moradias, em termos quantitativos, assim como a adequação dos domicílios, em termos qualitativos (ALVES; CAVENAGHI, 2006).

Dados recentes (CNDDS, 2008) informam que $53 \%$ da população brasileira ainda não tem acesso a saneamento adequado e, no atual ritmo de ampliação de acesso, a universalização somente se dará em 115 anos. Essa informação deve ser interpretada com cautela, pois, se forem consideradas as diferenças regionais e por estratos sociais, ou ainda de acordo com categorias de cor/ raça, o tempo para se atingir a universalização pode ser ainda bem maior.

O panorama das desigualdades entre indígenas e outros segmentos da sociedade observado no Brasil também se faz presente em outras regiões do mundo. Para uma enorme quantidade de povos indígenas, a escassez de informações confiáveis sobre a situação de saúde é uma recorrência. As informações disponíveis, apesar de escassas, apontam os indígenas sempre em desvantagem em relação a outros segmentos populacionais. Mesmo se tratando de países considerados desenvolvidos, como Austrália, a população autóctone (ou aborígene, como é o caso) vive, de modo geral, em condições mais precárias, inclusive no que

\footnotetext{
7 Ver questões 6.04 a 6.09 do questionário básico do Censo 2010, disponível em <http://biblioteca.ibge.gov.br/visualizacao/ instrumentos_de_coleta/doc2585.pdf>. Acesso em 08 nov. 2011.
} 
diz respeito à habitação (MONTENEGRO; STEPHENS, 2006; STEPHENS et al., 2006; KING et al., 2009; GRACEY; KING, 2009; UNITED NATIONS, 2009).

A questão da habitação dos indígenas no Brasil, no âmbito dos levantamentos censitários, é um tema que, por sua relevância, inclusive na área da saúde, está a demandar um tratamento teórico-metodológico mais refinado. Há um documento do IBGE do final da década de 1970 a respeito da situação dos domicílios brasileiros em área rural, que contém um capítulo cujo título é: "Habitação de economia primitiva - a casa do índio". Nele se lê:

A casa do indígena é o tipo mais primitivo e rústico que se conhece no Brasil. A aldeia reúne várias famílias, formando uma taba ou maloca comunal, a qual varia de tamanho de acordo com o número de ocupantes. A casa é coletiva (...) As malocas são agrupamentos de forma geralmente circular ou elíptica, em habitat concentrado, que reúnem habitações de tamanhos variáveis (COSTA, 1978 apud GALLOIS, 2004).

A ideia do "índio genérico" e que habita uma "casa genérica" é bastante presente no imaginário da sociedade nacional, ainda que haja amplas evidências demográficas e etnográficas da complexidade dessas categorias (AZEVEDO, 2003; PEREIRA et al., 2009). A visão de habitação indígena, tal qual descrita no texto acima, distancia-se bastante da ênfase na sociodiversidade presente na literatura antropológica. Neste contexto, há grande diversidade no que diz respeito às habitações dos indígenas no Brasil, que compõem complexos e diferenciados sistemas de organização sociocultural. Novaes (1983) afirma que, em contextos tradicionais, as sociedades indígenas adotam soluções específicas de habitação e cada uma delas concebe o espaço a ser habitado de forma distinta. ${ }^{8}$

As diferentes formas de habitar dos indígenas dizem muito da maneira como se apropriam e se adaptam ao meio ambiente. Alguns grupos concentram toda sua comunidade numa única casa, como os índios tuyuka e yanomami; para outros, a casa corresponde à unidade familiar, sendo ocupada pelo pai, mãe e filhos e seu número varia de aldeia para aldeia, como os wajãpi, do norte do Amapá. Em comunidades macro-jê (xavante e alguns grupos xinguanos), os indígenas edificam grandes aldeias circulares, onde há um centro, local de tomada de decisões, rituais e atividades integradoras. As casas que estão na periferia da aldeia são locais das atividades domésticas e de domínio feminino. São padrões de organizações diferentes daqueles observados nas sociedades ocidentais (NOVAES, 1983; TASSINARI, 1995).

Um dos achados mais significativos deste trabalho diz respeito à distribuição geográfica dos domicílios classificados como coletivos pelo Censo 2000. Pereira et al. (2009), a partir de um estudo sobre os xavante de Mato Grosso, destacaram que, dos 1.877 domicílios analisados para as áreas onde habitavam os xavante, $61,4 \%$ foram classificados como coletivos. Os autores concluíram que a maneira como os domicílios xavante foram classificados mostra como morfologias sociais nativas, distintas portanto daquelas ocidentais, foram percebidas e registradas pelos recenseadores. Na sociedade xavante, a posição das casas no semicírculo é definida por aspectos de ordem social e cultural. Tradicionalmente, os xavante são matrilocais, ou seja, após o casamento, os maridos vão morar na casa das esposas. Como é comum um conjunto de irmãos se casar com um conjunto de irmãs (ou que homem se case com duas ou mais irmãs), há um dado momento do ciclo de vida do domicílio no qual convivem várias gerações, não sendo incomum que 30 ou mais pessoas vivam sob o mesmo teto. Internamente às casas xavante, que em geral apresentam uma única entrada, há uma elaborada divisão do espaço, com cada casal e respectivos filhos ocupando locais demarcados e identificados pelas esteiras e cobertas dispostas no chão lado a lado. Não há paredes internas e as refeições são feitas

\footnotetext{
8 Sobre a diversidade de domicílios em diferentes sociedades indígenas, destaca-se a coletânea Habitações indígenas, organizada por Novaes (1983).
} 
em um espaço coletivo externo. Para os autores, essas e outras características podem ter levado os recenseadores a classificar os domicílios como coletivos.

Nas análises conduzidas neste trabalho, averiguou-se a distribuição dos domicílios indígenas classificados como coletivos nas diversas regiões do país, tendo-se constatado que houve uma importante concentração dessa classificação no Centro-Oeste, especificamente em Mato Grosso. O ponto central é que este tipo de classificação não foi um padrão constante em outras macrorregiões, ocorrendo de maneira concentrada neste Estado (de todos os domicílios coletivos "indígenas" do Brasil, 56,6\% estavam na área rural de municípios do Mato Grosso).

Outro ponto que surge a partir das análises aqui conduzidas é quanto a uma possível associação entre o tamanho das Terras Indígenas e a ocorrência de domicílios improvisados "indígenas" no Brasil. Isto porque esse tipo de domićlio foi mais frequente em regiões nas quais há sérios problemas fundiários relacionados às Terras Indígenas (municípios do Mato Grosso do Sul e Rio Grande do Sul, por exemplo). Nesses municípios, as Terras Indígenas são, em geral, muito pequenas em extensão territorial, o que, de acordo com Ricardo (2003), não garante boas condições de vida para os povos indígenas. Análises mais detalhadas se fazem necessárias para comprovar essa associação.

Há um importante aspecto de ordem metodológica no âmbito desse trabalho, qual seja, a utilização de agrupamento de municípios dentro e fora da Amazônia Legal. Nos municípios da Amazônia Legal, estão aproximadamente $99 \%$ da extensão das terras indígenas do Brasil (IBGE, 2005), o que é um fator que pode contribuir para melhores condições de vida (incluindo os padrões habitacionais) para os indígenas. E no restante das terras que estão fora da Amazônia Legal (1\%) que reside a população indígena para a qual foram registrados as maiores frequências de domicílios improvisados.

Outro aspecto importante refere-se aos debates sobre a captação de dados a respeito dos indígenas no âmbito dos censos demográficos não apenas no Brasil, mas também em diversas outras partes do mundo. Na América Latina, algumas características sobre os povos indígenas vêm sendo sistematicamente identificadas nos censos e diversos países têm ao menos uma questão específica sobre este segmento de suas respectivas populações. Em alguns, há maior aprofundamento nas investigações e são incluídas questões além da autodefinição, referentes a idioma falado e pertencimento étnico específico (SCHKOLINK; POPOLO, 2005). O Paraguai é exemplo de país que realiza censo específico para a população indígena, sendo que o mais recente foi feito em 2002, no qual foram investigados aproximadamente 17 mil domicílios indígenas, a maioria em área rural. No censo indígena paraguaio, levaram-se em conta não somente o tipo de habitação e o tipo de material na estrutura física das casas, mas também aspectos ambientais e as mudanças recentes (DGEEC, 2002).

Finalmente, no Brasil, a partir dos anos 1990, passaram a ser realizados alguns censos participativos com comunidades indígenas específicas. Azevedo (2003) conduziu em 1990-1992, com o auxílio de associações indígenas, o Censo Indígena Autônomo do Rio Negro (CIARN). No Baixo Amazonas, em 2002-2003, estudo com a população satere-mawé teve como objetivo fazer um censo participativo que visou conhecer a realidade sociodemográfica, ocupacional e das condições de vida deste povo (TEIXEIRA; BRASIL, 2005; TEIXEIRA et al., 2009). Esses dois levantamentos podem ser considerados pioneiros no sentido de terem sido feitos censos específicos voltados para indígenas no Brasil.

Certamente é um desafio a realização de levantamento censitário voltado especificamente para as populações indígenas no Brasil. A diversidade de etnias e a dimensão continental do país colocam barreiras importantes para a condução desses censos específicos. Ainda que não contemplando especificamente os indígenas, há iniciativas que podem vir a gerar dados importantes sobre esse segmento no Brasil em um futuro próximo. No Censo Demográfico 2010, o quesito sobre cor/ 
raça passou a fazer parte do questionário básico, de modo que foi perguntado para o universo da população brasileira. Além disso, conforme já mencionado, para os que se denominaram "indígenas", houve ainda o campo de resposta para identificação étnica e língua falada. Espera-se que esses novos elementos, que refletem

\section{Referências}

ABRASCO - Associação Brasileira de PósGraduação em Saúde Coletiva. Inquérito Nacional de Saúde e Nutrição dos Povos Indígenas: Relatório final. Rio de Janeiro, 2009.

ALVES, J. E. D.; CAVENAGHI, S. Déficit habitacional, famílias conviventes e condições de moradia. In: GUIMARÃES, J. R. S. (Orgs.). Demografia dos negócios: campo de estudo, perspectivas e aplicações. Campinas: Associação Brasileira de Estudos Populacionais, 2006, p. 257-286 (Série Demographicas, v. 3).

AZEVEDO, M. M. Demografia dos povos indígenas do Alto Rio Negro/AM: um estudo de caso de nupcialidade e reprodução. Tese (Doutorado). Campinas: Universidade Estadual de Campinas, 2003.

Povos indígenas na América Latina estão em processo de crescimento. In: RICARDO, C. A.; RICARDO, F. (Orgs.). Povos indígenas no Brasil 2001/2005. São Paulo: Instituto Socioambiental, 2006, p. 55-58.

CARDOSO, A. M.; SANTOS, R. V.; COIMBRA Jr., C. E. A. Mortalidade infantil segundo raça/cor no Brasil: o que dizem os sistemas nacionais de informação? Cadernos de Saúde Pública, Rio de Janeiro, v. 21, n. 5, p.1602-1608, 2005.

CHOR, D.; LIMA, C. R. A. Aspectos epidemiológicos das desigualdades raciais em saúde no Brasil. Cadernos de Saúde Pública, Rio de Janeiro, v. 21, n. 5, p. 15861594, 2005.

CNDSS - Comissão Nacional de Determinantes Sociais da Saúde. As causas sociais das iniqüidades em saúde no Brasil. Re- um aprimoramento dos instrumentos censitários, em particular se associados a um treinamento dos recenseadores para captar aspectos particulares inerentes aos povos indígenas, tragam aportes importantes para a compreensão da realidade indígena no país, sobretudo porque levará em considerações perfis étnicos específicos.

latório Final. Rio de Janeiro: Fiocruz, 2008. Disponível em: <http://www.cndss.fiocruz. $\mathrm{br} / \mathrm{pdf} / \mathrm{home} /$ relatorio.pdf $>$ Acesso em: 05 set. 2008 .

COIMBRA Jr., C. E. A.; SANTOS, R. V. Saúde, minorias e desigualdade: algumas teias de inter-relações, com ênfase nos povos indígenas no Brasil. Ciênc. Saúde Coletiva, Rio de Janeiro, v. 5, n. 1, p. 125-132, 2000.

DGEEC - Dirección General de Estadísticas, Encuestas y Censos. Atlas de las Comunidades Indígenas en el Paraguay. Assunción, Paraguay. Assunción, Dirección General de Estadísticas, Encuestas y Censo, 2002.

ESCOBAR, A. L.; RODRIGUES, A. F.; ALVES, C. L. M.; ORELLANA, J. D. Y.; SANTOS, R. V.; COIMBRA Jr., C. E. A. Causas de internação hospitalar indígena em Rondônia. $\mathrm{O}$ distrito sanitário especial indígena de Porto Velho (1998-2001). In: COIMBRA Jr., C. E. A.; SANTOS, R. V.; ESCOBAR, A. L. (Orgs.). Epidemiologia e saúde dos povos indígenas no Brasil. Rio de Janeiro: Fiocruz, 2003, p. 127-47.

GALLOIS, C. J. S. Sentidos e formas do habitar indígena: entre mobilidade e sedentarização. Estudo de caso entre os Wajãpi do Amapá. Dissertação (Mestrado). Rio de Janeiro, Universidade Federal do Rio de Janeiro, 2004.

GARNELO, L; MACEDO, G.; BRANDÃO, L. C. Os povos indígenas e a construção das políticas de saúde no Brasil. Brasília: Pan American Health Organization, 2003.

GRACEY, M.; KING, M. Indigenous health part 1: determinants and disease patterns. Lancet, n. 374, p. 65-75, 2009. 
IBGE - Instituto Brasileiro de Geografia e Estatística. Sinopse preliminar do Censo Demográfico 2000. Rio de Janeiro, 2000.

Tendências demográficas. Uma análise dos indígenas com base nos resultados da amostra dos Censos Demográficos 1991 e 2000. Rio de Janeiro, 2005.

KENNEDY, D. P.; STEPHEN, G. P. Who are Brazil's indígenas? Contributions of census data analysis to anthropological demography of indigenous populations. Human Organization, v. 59, n. 3, p. 311324, 2000.

KING, M.; SMITH, A.; GRACEY, M. Indigenous health part 2: the underlying causes of the health gap. Lancet, n. 374, p. 76-85, 2009.

LUDWIG, K. M.; FREI, F.; ÁLVARES FILHO, F.; RIBEIRO-PAES, J. T. Correlação entre condições de saneamento básico e parasitoses intestinais na população de Assis, estado de São Paulo. Rev. Soc. Bras. Med. Trop., São Paulo, v. 32, n. 5, p. 547-555, 1999.

MONTENEGRO, R. A.; STEPHENS, C. Indigenous health in Latin America and the Caribbean. Lancet, n. 367, p.1859-1869, 2006.

MURA, F.; ALMEIDA, R. F. T. GuaraniKaiowa. Povos Indígenas no Brasil (Instituto Socioambiental), 2003. Disponivel em: $<$ www.socioambiental.org $>$. Acesso em: 18 nov. /2009.

NOVAES, S. C. (Org.). Habitações indígenas. São Paulo: Nobel/ Edusp, 1983.

OLIVEIRA, S. M. M. C. Mortalidade infantil e saneamento básico: ainda uma velha questão. In: XVI ENCONTRO NACIONAL DE ESTUDOS POPULACIONAIS. Anais... Caxambu, Abep, 2008. Disponível em: <http://www.abep.nepo.unicamp.br/ encontro2008/docsPDF/ABEP2008_959. pdf>. Acesso em: 14 mar. 2009.

OLIVEIRA, P. T. R. Desigualdade regional e o território da saúde na Amazônia. Belém: EDUFPA, 2008.

PAGLIARO, H.; AZEVEDO, M. M.; SANTOS, R. V. (Orgs.). Demografia dos povos indígenas no Brasil. Rio de Janeiro: Editora Fiocruz/Associação Brasileira de Estudos Populacionais, 2005.

PEREIRA, N. O. M.; AZEVEDO, M. M.; SANTOS, R. V. Perfil demográfico e socioeconômico das pessoas que se autodeclararam indígenas no Brasil. In: PAGLIARO, H.; AZEVEDO, M. M.; SANTOS, R. V. (Orgs.). Demografia dos Povos indígenas no Brasil. Rio de Janeiro: Editora Fiocruz/Associação Brasileira de Estudos Populacionais, 2005, p. 155-166.

PEREIRA, N. O. M. Importância dos censos nacionais no conhecimento da demografia e da saúde dos indígenas do Brasil. Indicadores Sociodemográficos e de Saúde no Brasil 2009. Estudos e Pesquisas: Informação demográfica e socioeconômica. Rio de Janeiro, n. 25, IBGE, 2009.

PEREIRA, N. O. M.; SANTOS, R. V.; WELCH, J. R.; COIMBRA Jr., C. E. A.; SOUZA, L. G. Demography, territory, and identity of indigenous peoples in Brazil: the xavante indians and the 2000 brazilian national census. Human Organization, v. 68, n. 2, p.166-180, 2009.

PERZ, S. G.; WARREN, J.; KENNEDY, D. P. Contributions of racial-ethnic reclassification and demographic processes to indigenous population resurgence the case of Brazil. Latin American Research Review, v. 43, n. 2, p. 7-33, 2008.

RICARDO, C. A. Fome Zero e os povos indígenas - Quem tem fome de quê? São Paulo, ISA, 2003. Disponível em: <www. socioambiental.org >. Acesso em: 18 nov. 2009.

SANTOS, R. V.; CARDOSO, A. M.; GARNELO, L.; COIMBRA Jr., C. E. A.; CHAVES, M. B. Saúde dos povos indígenas e políticas públicas no Brasil. In: GIOVANELLA, L. (Org.). Políticas e sistemas de saúde no Brasil. Rio de Janeiro: Editora Fiocruz, 2008, p. 1035-1056.

SANTOS, R. V.; COIMBRA Jr., C. E. A. Saúde Indígena. As causas sociais das iniquidades no Brasil. Rio de Janeiro: Editora Fiocruz, 2008, p. 121-128 (Relatório Final 
da Comissão Nacional sobre Determinantes Sociais da Saúde - CNDSS).

SANTOS, R. V.; COIMBRA Jr., C. E. A. Cenários e tendências da saúde e da epidemiologia dos povos indígenas no Brasil. In: COIMBRA Jr., C. E. A.; SANTOS, R. V.; ESCOBAR, A. L. (Orgs.). Epidemiologia e saúde dos povos indígenas no Brasil. Rio de Janeiro: Editora Fiocruz; 2003, p. 13-47.

SCHKOLINK, S.; POPOLO, F. Los censos e los pueblos indígenas en America Latina: una metodología regional. Seminário internacional "Pueblos indígenas de América Latina y el caribe: relevancia y pertinencia de la información sociodemografica para politicas y programas. Santiago, Cepal, 2005.

STEPHENS, C.; PORTER, J.; NETTLETON, C.; WILLIS, R. Disappearing, displaced, and undervalued: a call to action for Indigenous health worldwide. Lancet, n. 367, p. 2019-2028, 2006.

TASSINARI, A. M. I. Sociedades indígenas: introdução ao tema da diversidade cultural. In: SILVA, A. L.; GRUPIONI, L. D. B. (Orgs.). A temática indígena na escola: novos subsídios para professores de 1 e 2 graus. Brasília: MEC/Mari/Unesco, 1995, p. 445-479.
TEIXEIRA, P.; BRASIL, M. Estudo demográfico dos Sateré-Mawé: um exemplo de censo participativo. In: PAGLIARO, H.; AZEVEDO, M. M.; SANTOS, R. V. (Orgs.). Demografia dos povos indígenas no Brasil. Rio de Janeiro: Editora Fiocruz, 2005, p. 135-154.

TEIXEIRA, P.; MAINBOURG, E. M. T.; BRASIL, M. Migração do povo indígena Sateré-Mawé em dois contextos urbanos distintos na Amazônia. Cad. CRH, Salvador, v. 22, n. 57, 2009.

UNITED NATIONS. State of the world's indigenous people. New York, 2009.

The perspective of information received and collected within the context of ILO Conventions n. 107 and 169, and other relevant ILO Conventions. Equality and Employment Branch, International Labour Office. Workshop on data collection and disaggregation for indigenous peoples. New York, 2004

WALDMAN, E. A.; SILVA, L. J.; MONTEIRO, C. A. Trajetória das doenças infecciosas: da eliminação da poliomielite à reintrodução da cólera. In: MONTEIRO, C. A. (Org.). Velhos e novos males da saúde no Brasil - a evolução do país e de suas doenças. São Paulo: Hucitec, 1995, p. 195-244.

\section{Resumen}

Clasificación de los domicilios "indígenas" en el Censo Demográfico 2000: subsidios para el análisis de condiciones de salud

La caracterización de los domicilios en la recogida de datos censitarios, que incluye las condiciones de la vivienda, saneamiento básico, entre otros aspectos, junto al perfil socioeconómico de los habitantes, es de gran importancia en el análisis sobre condiciones de salud. En Brasil, se acumulan evidencias de que los pueblos indígenas presentan desigualdades importantes en relación a otros segmentos de la sociedad, con tasas de morbimortalidad en general más pronunciadas. En base a los microdatos del Censo Demográfico 2000, este trabajo analiza las frecuencias de domicilios cuyos responsables se autoclasificaron como "indígenas" y que residían en un domicilio colectivo o improvisado en el área rural de los municipios brasileños. Para esas dos posibilidades de clasificación, no se investigan las características de los domicilios. En el análisis dirigido a los grupos de color/raza, los "indígenas" fueron los que tuvieron las mayores proporciones de domicilios colectivos, más frecuentes en el CentroOeste, específicamente en Mato Grosso. Las frecuencias de domicilios "improvisados indígenas" también fueron superiores a los de no-indígenas, incluyendo "blancos", "negros" y "mulatos". Al contrario de los colectivos, los domicilios improvisados "indígenas" se daban en diferentes 
regiones de Brasil, resaltando especialmente los municipios en la macrorregión Sur y en Mato Grosso do Sul. Respecto a los municipios localizados fuera de la Amazonía Legal, donde en general las Tierras Indígenas presentan pequeñas dimensiones, hubo 1,5 más domicilios "indígenas" clasificados como improvisados que en la Amazonía Legal. Se argumenta que, en parte, las más elevadas frecuencias de domicilios colectivos "indígenas" se puedan deber a problemas de clasificación por parte del censo, puesto que las sociedades indígenas presentan estructuras sociales y familiares propias. Los análisis indican una necesidad de perfeccionar la forma de captación de datos sobre las características domiciliarias de los "indígenas", en el ámbito de las recogidas de datos dirigidos por el IBGE. Solamente generando esta información, a la par que considerando la diversidad étnica existente en Brasil, será posible disminuir la "invisibilidad demográfica y epidemiológica" de los pueblos indígenas y, consecuentemente, enfrentarse a las desigualdades en salud.

Palabras-clave: Demografía indígena. Censos Demográficos. Desigualdades en salud.

\section{Abstract \\ Classification of "indigenous" households in the 2000 Demographic Census: elements for the analysis of health status}

The characterization of households during censuses, including dwelling conditions, basic sanitation, among other aspects, along with the socioeconomic profile of dwellers, is extremely important to analyze health status. In Brazil, there has been accumulated evidence that indigenous populations, in general, are subject to major inequalities with more pronounced morbidity and mortality, in comparison to other segments of society. Based on the micro data of the 2000 Demographic Census, the present study analyzed the frequency of households whose heads classified them as "indigenous" and that the household was collective or improvised, in the rural area of Brazilian municipalities. The characteristics of households were not studied for neither of the classification possibilities. In the analysis by color/race groups, "indigenous" peoples had the higher proportion of collective households, more frequent in the Center-West, more specifically in Mato Grosso. The frequency of "improvised indigenous" households was also higher than for non-indigenous, including "white", "black" and "brown" individuals. Different from collective households, improvised "indigenous" households were seen in different regions of Brazil, especially in municipalities of the macro region south and in Mato Grosso do Sul. For municipalities located outside the Legal Amazon regions, where in general Native Lands are of small size, there were 1.5 more "indigenous" households classified as improvised than in the Legal Amazon. An argument is that the higher frequency of collective "indigenous" households are partly due to Census classification problems, given indigenous societies have their own social and family morphologies. The analyses indicate the need to improve the attainment of data on the characteristics of "indigenous" households in surveys conducted by the IBGE. Decreasing the "demographic and epidemiological invisibility" of indigenous populations and, consequently, facing the inequalities in health, will only be possible by generating information that takes into account the ethnical diversity of Brazil.

Keywords: Indian demography. Demographic census. Health inequalities.

Recebido para publicação em 01/06/2010

Aceito para publicação em 06/02/2011 